\title{
Experimental and theoretical study on chiral recognition mechanism of ketoconazole enantiomers using heptakis (2,3,6-tri-O-methyl)- $\beta$-cyclodextrin
}

\author{
Wan Aini Wan Ibrahim ${ }^{1,2 *}$, Siti Rosilah Arsad ${ }^{1}$, Hasmerya Maarof $^{1,2 *}$, Mohd Marsin Sanagi ${ }^{2,3}$ \\ ${ }^{I}$ Separation Science \& Technology Group (SepSTec), Department of Chemistry, Faculty of Science, UTM, 81310 UTM Johor Bahru, Johor, Malaysia \\ ${ }^{2}$ Nanotechnology Research Alliance, Universiti Teknologi Malaysia, 81310 UTM Johor Bahru, Johor, Malaysia \\ ${ }^{3}$ Ibnu Sina Institute for Fundamental Science Studies, Universiti Teknologi Malaysia, 81310 UTM Johor Bahru, Johor, Malaysia. \\ *Corresponding Authors: wanaini@kimia.fs.utm.my; waini@utm.my (Wan Aini Wan Ibrahim), hasmerya@kimia.fs.utm.my (Hasmerya Maarof)
}

\section{Article history :}

Received 4 January 2014

Revised 24 April 2014

Accepted 22 May 2014

Available online 5 June 2014

\section{GRAPHICAL ABSTRACT}

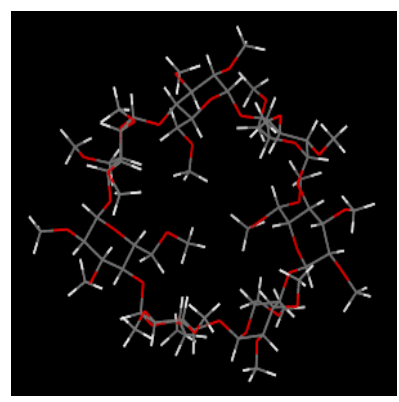

\begin{abstract}
Capillary electrokinetic chromatography (EKC) has been established as a versatile and robust capillary electrophoresis (CE) method for the separation of enantiomers. One of the most attractive advantages of EKC for the separation of enantiomers is its ease of change of separation media in method development. The separation solution can easily be altered to find the optimum separation media and one can also use an expensive chiral selector because small amounts of it are required. This work aims to develop experimental and theoretical analysis of the chiral separation of ketoconazole using EKC and molecular modelling study, respectively. In the first part of the study, several cyclodextrins (CDs) as the chiral selectors (CS) namely $\alpha$-cyclodextrin, sulfated $\beta$-cyclodextrin, (2-hydroxylpropyl)- $\beta$-cyclodextrin, heptakis (2,6-di-O-methyl)- $\beta$-cyclodextrin, and heptakis (2,3,6-tri-O-methyl)- $\beta$-cyclodextrin were screened. CDs were initially chosen as they are easily available and cheap. Heptakis (2,3,6-tri-O-methyl)$\beta$-cyclodextrin $(\mathrm{TM} \beta \mathrm{CD})$ exhibited a higher enantioselectivity power compared with other tested CDs. The influence of TM $\beta C D$ concentration, buffer $\mathrm{pH}$, buffer concentration, separation temperature and applied voltage were investigated. The optimum conditions for chiral separation of ketoconazole was achieved using $10 \mathrm{mM}$ phosphate buffer at $\mathrm{pH} 3.0$ containing $20 \mathrm{mM}$ TMBCD with an applied voltage of $30 \mathrm{kV}$ at $35^{\circ} \mathrm{C}$ with $5 \mathrm{~s}$ injection time (hydrodynamic injection). The ketoconazole enantiomers were resolved in less than $7 \mathrm{~min}\left(\mathrm{R}_{s}=1.79\right)$. In order to understand possible chiral recognition mechanisms of ketoconazole with TM $\beta C D$, host-guest binding procedures of TM $\beta C D$ and ketoconazole were studied using the semi-empirical PM3 calculations.
\end{abstract}

Keywords: Capillary electrokinetic chromatography (EKC), Chiral separation, Cyclodextrin Ketoconazole, Molecular modelling, PM3

\section{INTRODUCTION}

Ketoconazole, [IUPAC name: 1-acetyl-4-[4-[[2(2,4-dichlorophenyl)-2-(1H-imidazol-1-yl-methyl)-1,3dioxolan-4-yl]methoxy]phenyl]piperazine], $\left(\mathrm{pK}_{\mathrm{a}}=2.95\right.$ and 6.54 ) is known as a potent, orally active, broad-spectrum antifungal agent [1], which is marketed as a racemic mixture of the cis- $(2 \mathrm{~S}, 4 \mathrm{R})$ and $-(2 \mathrm{R}, 4 \mathrm{~S})$ enantiomers $[2,3]$. The cis configuration for these molecule means that the hydrogen and the 2,4-dichlorophenyl group at the two stereogenic (chiral) centre, respectively, are on the same side of the five-membered (dioxolane) ring [4]. Ketoconazole is an imidazole antifungal administered orally or topically. It has been given for the prophylaxis of fungal infections in immuno-compromised patients. The usual oral dose for treatment and prophylaxis of fungal infections is $200 \mathrm{mg}$ once daily. Ketoconazole is applied topically as a $2 \%$ cream or a shampoo [5].

Enantioseparation by using CE offers a few advantages such as very high efficiencies and the ease of method development. Low consumption of both analyte and chiral selector and the short analysis time makes it a very good alternative for analytical separation of enantiomers compared with HPLC [6]. An important method for separating enantiomers involves cyclodextrin (CD) as a chiral selector [7]. Heptakis (2,3,6-tri- $O$ methyl)- $\beta$-cyclodextrin (TM $\beta C D$ ) also known as permethyl- $\beta$-cyclodextrin is a derivative of cyclodextrin modified from $\beta$-cyclodextrin by substituting the 2,3 , 6$\mathrm{OH}$ groups of $\beta$-cyclodextrin with methyl group. The ability of $\mathrm{TM} \beta C D$ in chiral recognition looks quite promising as compared with other permethylated CDs [8]. The growing interest in molecular modelling studies on the formation and stability of inclusion complexes of cyclodextrin with a variety of molecules has prompted us to perform a computational technique in combination with capillary electrophoresis (CE) for a deeper understanding of the chiral recognition mechanism of ketoconazole. The four stereoisomers of ketoconazole are given in Fig. 1. 


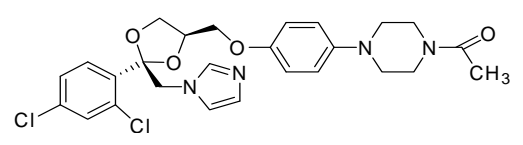

2S4R

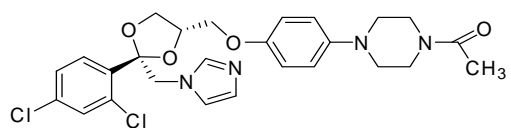

2R4S
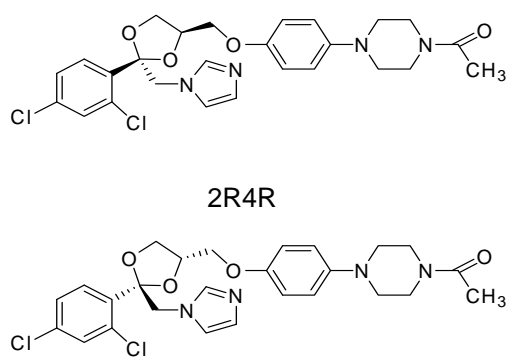

2S4S

Fig. 1 Stereoisomers of ketoconazole

\section{EXPERIMENTAL}

\subsection{Materials, method and instruments}

All electropherograms were obtained with the Agilent capillary electrophoresis system from Agilent Technologies (Waldbronn, Germany), equipped with temperature control and diode array detection (DAD). Separations were performed using an untreated fused silica capillary of $64.5 \mathrm{~cm} \times 50 \mu \mathrm{m}$ i.d. (with an effective length of $56 \mathrm{~cm}$ to the detector window) obtained from Polymicro Technologies (Phoenix, AZ, USA). Ketoconazole and TM $\beta C D$ were purchased from SigmaAldrich (St. Louis, MO, USA). Sodium hydroxide and disodium hydrogen phosphate 12-hydrate were purchased from Riedel-de Haen (Seelze, Germany). All other chemicals and solvents were common brands of analytical-reagent grade. Water used for dilutions or as buffer preparation was produced from a Water Purification System from Millipore (Molsheim, France).

\subsection{Preparation of stock, working standard and background electrolyte solution}

A stock solution containing $1 \mathrm{mg} \mathrm{mL} \mathrm{m}^{-1}$ of each analytes was prepared in HPLC grade methanol from Merck (Darmstadt, Germany) and stored at $4{ }^{\circ} \mathrm{C}$ and protected from light. Standard solutions were prepared by diluting the stock solution. Working standards solutions for the separation of enantiomers were prepared by diluting each of the stock solutions with HPLC grade methanol. A stock of $200 \mathrm{mM}$ phosphate buffer was prepared by dissolving $0.7163 \mathrm{~g}$ of disodium hydrogen phosphate 12 hydrate using deionized water in a $10 \mathrm{~mL}$ volumetric flask. The buffer solution was then diluted to the mark after solution was adjusted to $\mathrm{pH} 3.0$ using $50 \mathrm{mM}$ phosphoric acid. The background electrolyte (BGE) solution was prepared by diluting the phosphate buffer solution to 40 $\mathrm{mM}$ and addition of $20 \mathrm{mM}$ TM $\beta C D$. All separation solutions were filtered through $0.20 \mu \mathrm{m}$ nylon syringe filter from Whatman (Clifton, $\mathrm{NJ}$ ) to remove any impurities.

\subsection{Molecular modelling study}

The crystalline structure of TM $\beta C D$ (code: XAQJII) was obtained from Cambridge Crystal Structure Database in cif file format. The structure was converted into mol file format using the Mercury software. Then, four stereoisomers of ketoconazole were drawn using ChemSketch and converted into 3D model using MS Modelling. The complexes of ketoconazole and TM $\beta C D$ were built using MS Modelling application. All the calculations were performed with Gaussian 03 software [9]. PM3 quantum-mechanical semi-empirical method was performed in order to investigate the formation of mechanism of ketoconazole and TM $\beta C D$ complexes. The binding energy $(\Delta E)$ upon complexation between ketoconazole and TM $\beta C D$ was calculated for the minimum energy structure using Eq. 1:

$\Delta E=E_{\text {complex }}-\left(E_{K T Z}+E_{T M \beta C D}\right)$

\section{RESULTS \& DISCUSSION}

\subsection{Optimization of the EKC conditions}

Chiral separation of ketoconazole was explored using TM $\beta C D$ as chiral selector (CS). Previous work by Castro-Puyana et al. [10,11] successfully separated two enantiomers of ketoconazole. However, the use of high concentration of phosphate buffer $(100 \mathrm{mM})$ as BGE is not favourable as it generates high current and possible Joule heating [12]. The current work focused on the optimization process for the enantioseparation of ketoconazole using more favourable conditions and theoretical studies of complexation of ketoconazole with TM $\beta C D$ using computer modelling. For the optimization process, the $T M \beta C D$ concentration was first varied in order to achieve the best separation of the ketoconazole enantiomers by CD-EKC. The TM $\beta C D$ concentration range was optimized from 3 to $30 \mathrm{mM}$ in $40 \mathrm{mM}$ phosphate buffer solution, $\mathrm{pH}$ 3.0. The best resolution $\left(\mathrm{R}_{\mathrm{s}}=3.80\right)$ for ketoconazole enantiomers were obtained using $20 \mathrm{mM} T \mathrm{TM} \beta \mathrm{CD}$ with an analysis time of $13 \mathrm{~min}$ (data not shown). 
The effect of phosphate buffer $\mathrm{pH}$ and buffer concentration on the enantioseparation of ketoconazole was also investigated. Chiral separation of ketoconazole was investigated in the $\mathrm{pH}$ range from 2.5 to 5.0 (with 20 $\mathrm{mM}$ TM $\beta C D$ in $40 \mathrm{mM}$ phosphate buffer). The best enantioseparation was obtained at $\mathrm{pH} 3.0\left(\mathrm{R}_{\mathrm{s}}=4.66\right)$ (Fig. 2 ). In addition, increasing phosphate buffer concentration from 5 to $50 \mathrm{mM}$ resulted in an increase of migration time of enantiomers but the resolutions were not significantly increased. Optimum concentration chosen for phosphate buffer ( $\mathrm{pH}$ 3.0) was $10 \mathrm{mM}$, since it yielded good resolution $\left(\mathrm{R}_{\mathrm{s}}=2.03\right)$ with relatively short migration time $(\sim 10 \mathrm{~min})$ (data not shown).

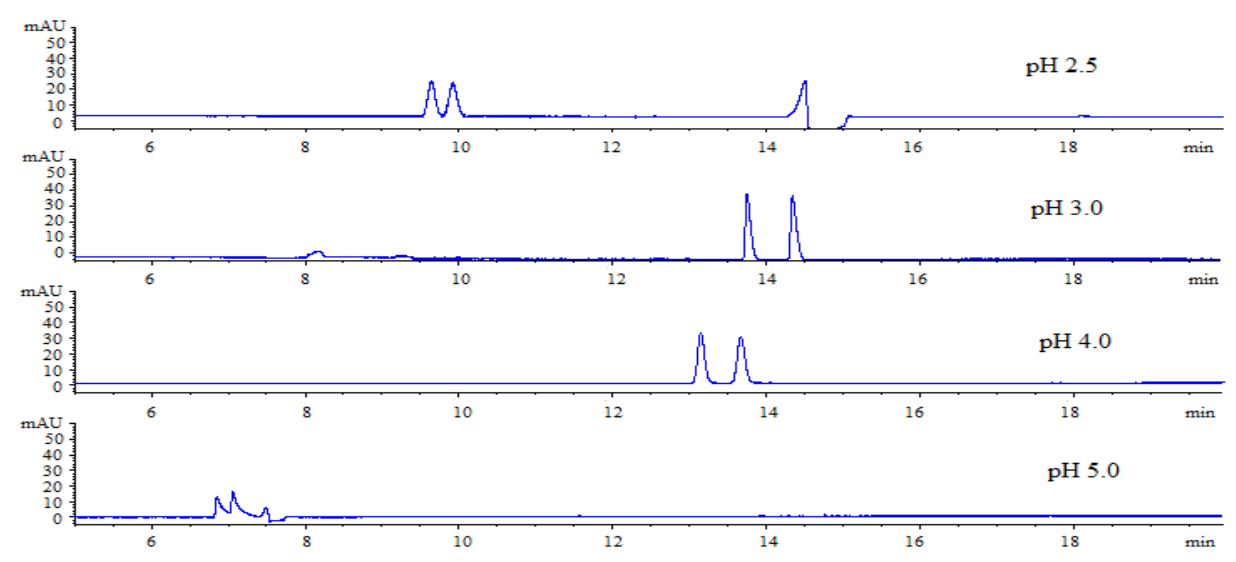

Fig. 2 Enantioresolution of ketoconazole using CD-EKC at different buffer $\mathrm{pH}$ (Separation solution: phosphate buffer $\mathrm{pH}$ 2.5-5.0, 20 $\mathrm{mM} \mathrm{TM} \beta C D$ in $40 \mathrm{mM}$ phosphate buffer; capillary, $64.5 \mathrm{~cm} \times 50 \mu \mathrm{m}$ I.D. (effective length, $56 \mathrm{~cm}$ ); applied voltage, $25 \mathrm{kV}$; temperature, $25^{\circ} \mathrm{C}$; detection wavelength, $200 \mathrm{~nm}$; hydrodynamic injection, 50 mbar for $5 \mathrm{~s}$; analyte concentration, $100 \mathrm{mg} \mathrm{L}^{-1}$ )

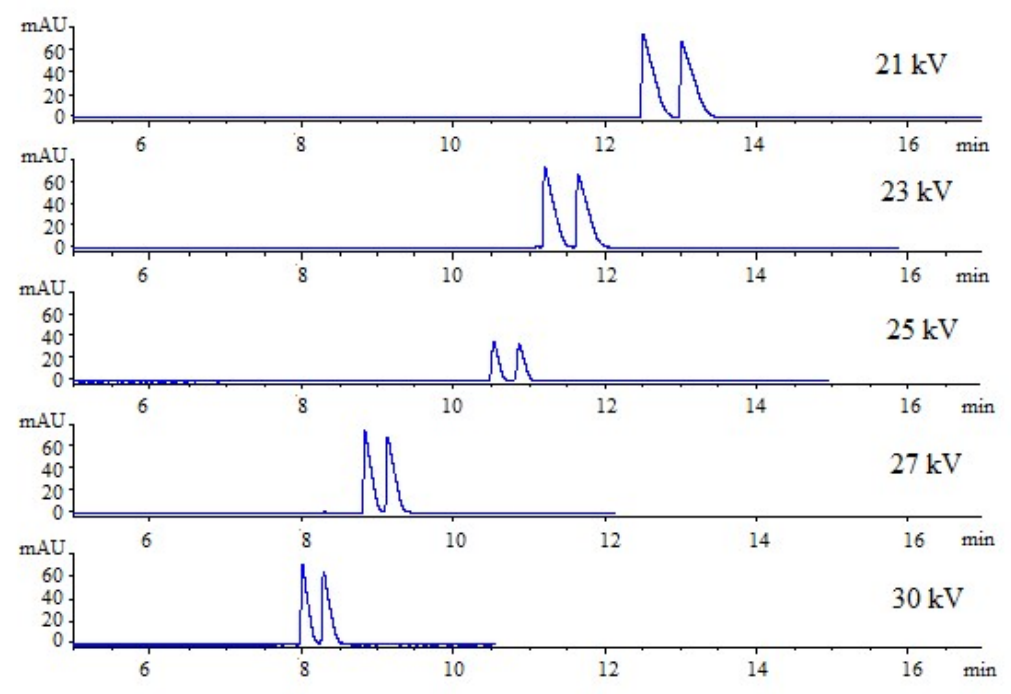

Fig. 3 Enantioresolution of ketoconazole using CD-EKC at different voltage. Separation conditions: applied voltage $21-30 \mathrm{kV} ; 20 \mathrm{mM}$ $\mathrm{TM} \beta \mathrm{CD}$ in $10 \mathrm{mM}$ phosphate buffer; $\mathrm{pH} 3.0$; temperature, $25^{\circ} \mathrm{C}$; other condition are as in Fig. 2

In order to improve the migration time for the separation of ketoconazole enantiomers, the effect of separation voltage $(25 \mathrm{kV}$ to $30 \mathrm{kV})(($ Fig. 3) and separation temperature $\left(15^{\circ} \mathrm{C}\right.$ to $40^{\circ} \mathrm{C}$ ) (data not shown) were explored. The migration time was found to be inversely proportional to the increase in separation voltage and temperature. It is important to note that the highest voltage for the separation in EKC cannot exceed $30 \mathrm{kV}$. Therefore, $30 \mathrm{kV}$ was chosen as the optimum voltage for the separation of ketoconazole. The best chiral separation of ketoconazole was obtained within 6.5 min with a BGE containing $20 \mathrm{mM} \mathrm{TM} \beta C D$ in $10 \mathrm{mM}$ phosphate buffer at $\mathrm{pH} 3.0$, applied voltage $30 \mathrm{kV}, 35^{\circ} \mathrm{C}$ separation temperature and $5 \mathrm{~s}$ hydrodynamic injection time (Fig. 4). 


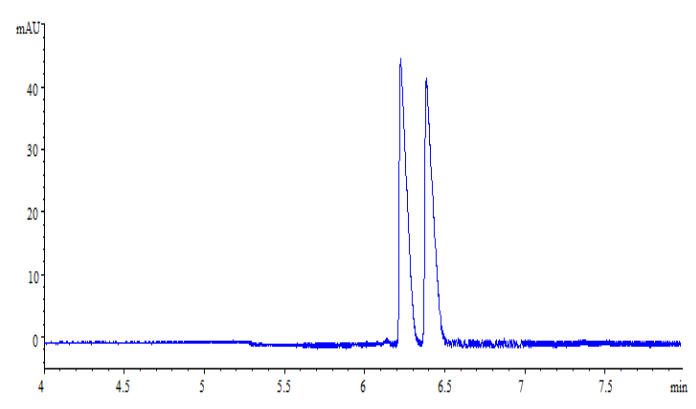

Fig. 4 Enantioresolution of ketoconazole using optimum CDEKC conditions. Separation conditions: $20 \mathrm{mM}$ TM $\beta C D$ in 10 $\mathrm{mM}$ phosphate buffer; $\mathrm{pH} 3.0$; voltage, $30 \mathrm{kV}$; temperature, $35^{\circ} \mathrm{C}$; other conditions are as in Fig. 2.
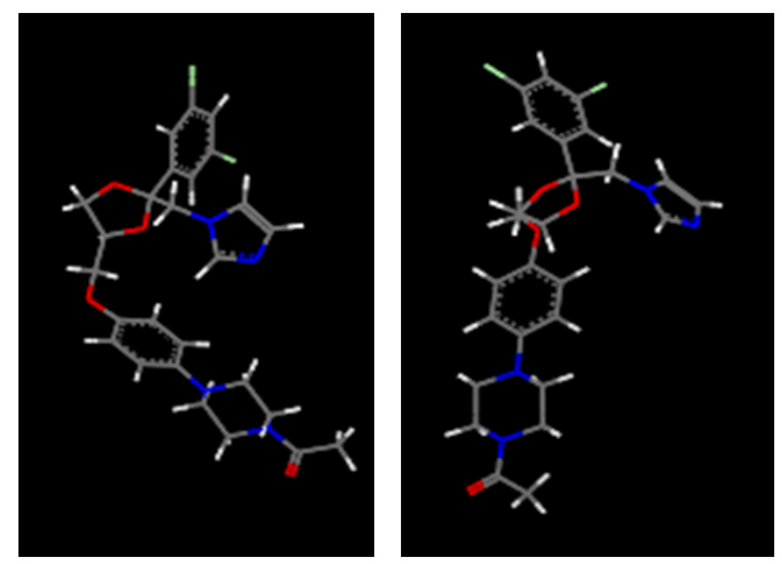

2S4R

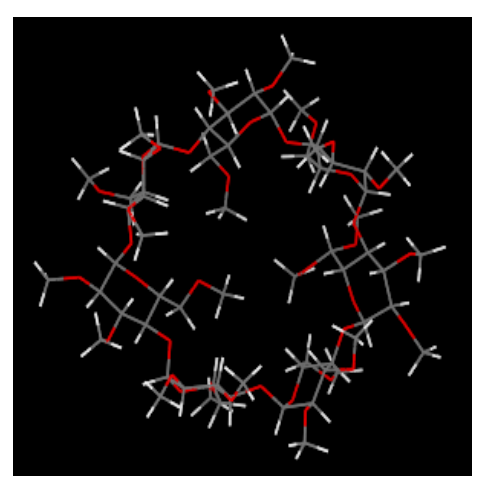

Fig. $5 \mathrm{TM} \beta \mathrm{CD}$ structure in $3 \mathrm{D}$ view with minimum energy: [grey: carbon; red: oxygen; white: hydrogen]

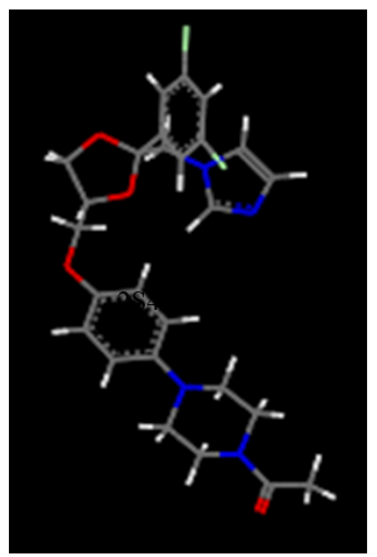

2R4S

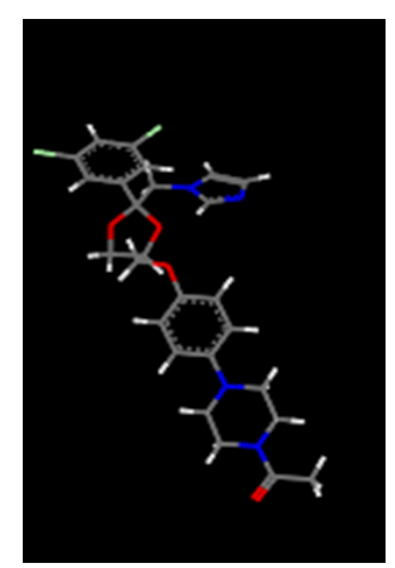

2S4S

Fig. 6 Ketoconazole stereoisomers structure in 3D view with minimum energy [grey: carbon; blue: nitrogen; green: chlorine; red: oxygen; white: hydrogen]

Table 1 Optimized energies of TM $\beta C D$ and ketoconazole stereoisomers

\begin{tabular}{|c|c|c|c|c|c|}
\hline & & \multicolumn{4}{|c|}{ Energy $\left(\mathrm{kJ} \mathrm{mol}^{-1}\right)$} \\
\hline \multicolumn{2}{|c|}{ Single TM $\beta C D$} & \multicolumn{4}{|c|}{-5684.25} \\
\hline & & 2R4R & 2R4S & 2S4R & $2 \mathrm{~S} 4 \mathrm{~S}$ \\
\hline \multicolumn{2}{|c|}{ Single ketoconazole } & -314.48 & -325.58 & -325.15 & -314.34 \\
\hline \multirow{2}{*}{ Complexes (Model A) } & Top & -6630.62 & -5840.22 & -6068.26 & -6002.35 \\
\hline & Bottom & -5777.28 & -6128.77 & -6235.60 & -6257.91 \\
\hline \multirow{2}{*}{ Complexes (Model B) } & Top & -5860.24 & -6045.68 & -6057.20 & -6045.68 \\
\hline & Bottom & -5691.24 & -6070.53 & -5999.05 & -6036.40 \\
\hline
\end{tabular}

\subsection{Molecular modelling calculation}

Molecular modelling proved to be an excellent tool to identify the host-guest interaction in drug-cyclodextrin technology in order to calculate the binding energy $(\Delta E)$ as well as the geometrical structure of the inclusion complex $[3,13]$. PM3 is highly convenient for the modelling of large molecular systems and performs better than AM1 in biochemical systems due to its improved description of the interaction between non-bonded atoms [14]. The current studies were performed by using molecular mechanics calculations (PM3 semi-empirical methods and Gaussian 03) to calculate the relative energies involving the four possible inclusion forms of complexes.

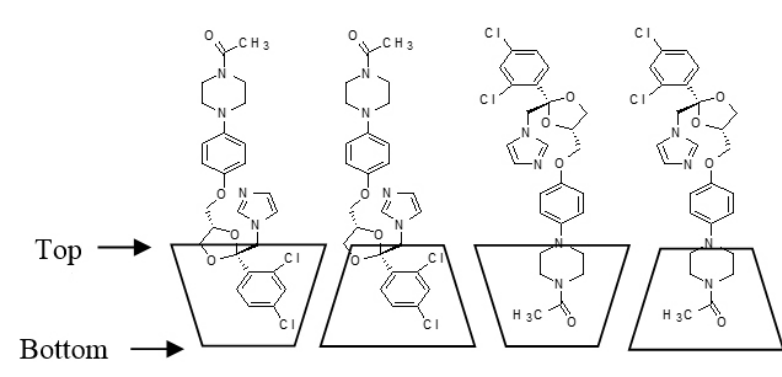

Model A

Model B

Scheme 1 Four possible inclusion complexes 
Fig 5 and Fig 6 shows the minimum energy structure of TM $\beta C D$ and ketoconazole stereoisomers. The optimized energies of the single structure of TM $\beta C D$, ketoconazole stereoisomers and complexes of Model A and Model B in $\mathrm{kJ} \mathrm{mol}^{-1}$ are summarized in Table 1.

The inclusion complexes were built from these optimized single structures and further optimization calculation of each complex was calculated with the four possible inclusion forms. The schematic diagram for the possible inclusion complexation is shown in Scheme 1.

Four possible inclusions complexes are defined as different in arrangement for the inclusion modes. For the four possible inclusions complexes, we separated into Model A and Model B. Both models have two different orientations of TM $\beta C D$; top and bottom. The difference in Model A and B is the orientation of ketoconazole structure to form the inclusion complexes into the TM $\beta C D$ cavity. The binding energies for Model A and Model B were calculated and summarized in Table 2 .

From Table 2, it shows that 2R4R/TM $\beta$ CD complex form the most stable inclusion complex with the lowest binding energy, $\Delta E=-631.27$ when added from the top of TM $\beta C D$ cavity. However, the inclusion complex is not favourable with the other different inclusion orientation of $2 \mathrm{R} 4 \mathrm{R}$ into $\mathrm{TM} \beta C D$ cavity. For $2 \mathrm{R} 4 \mathrm{~S} / \mathrm{TM} \beta C D$ and $2 \mathrm{~S} 4 \mathrm{R} / \mathrm{TM} \beta \mathrm{CD}$ complexes, only one arrangement does not allow the complexation to occur which is inclusion from the top of cavity of the TM $\beta C D$ and from bottom of cavity of the TM $\beta C D$ with different orientation (Model B) of stereoisomers structure, respectively. Conversely, 2S4S/ TM $\beta C D$ complex favour inclusion complexation for all arrangement and orientation of structures with the lowest binding energy, $\Delta E=-259.32 \mathrm{~kJ} / \mathrm{mol}$. Fig. 7 shows the most stable inclusion complex for each stereoisomer.

Table 2 Binding energies of $\mathrm{TM} \beta \mathrm{CD}$ and ketoconazole complexes.

\begin{tabular}{lcccc}
\hline \multirow{2}{*}{ Complexes } & \multicolumn{4}{c}{ Binding Energy, $\Delta \mathrm{E}\left(\mathrm{kJ} \mathrm{mol}{ }^{-1}\right)$} \\
\cline { 2 - 5 } & $\begin{array}{c}\text { Model A } \\
\text { (Top) }\end{array}$ & $\begin{array}{c}\text { Model A } \\
\text { (Bottom) }\end{array}$ & $\begin{array}{c}\text { Model B } \\
\text { (Top) }\end{array}$ & $\begin{array}{c}\text { Model B } \\
\text { (Bottom) }\end{array}$ \\
\hline 2R4R/ TMBCD & -631.27 & 221.45 & 138.49 & 307.49 \\
2R4S/ TMBCD & 169.61 & -118.94 & -35.85 & -60.70 \\
2S4R/ TMBCD & -58.86 & -226.20 & -47.80 & 10.35 \\
2S4S/TMBCD & -3.76 & -259.32 & -47.09 & -37.81 \\
\hline
\end{tabular}

It can be deduced from the computational calculations that the stability of the inclusion complexes between the enantiomers and the $\mathrm{CD}$ allows chiral discrimination and thus leads to different migration times as observed in the experimental studies [15]. This finding is consistent with findings from previous works by Bernal et al. [16], Lin et al. [17] and Castro-Puyana et al. [10,11]. However, from the computer modelling study, the binding energy of the complexes proves that all the stereoisomers of ketoconazole were possible to be formed with the $\mathrm{TM} \beta C D$. Further study is in progress to attempt to separate all four stereoisomers of ketoconazole using dual CD method. In addition, the optimization of PM3 semiempirical method will be further simulated using different distance and angle inclusion of ketoconazole stereoisomers for more insight to the understanding the mechanism of the complexes formed and the interaction/s involved.

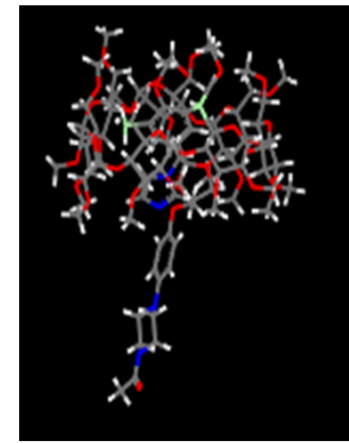

2R4R

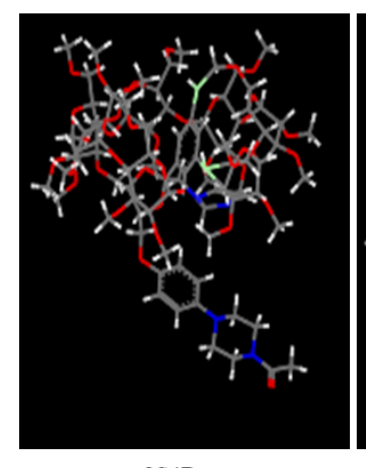

$2 \mathrm{~S} 4 \mathrm{R}$

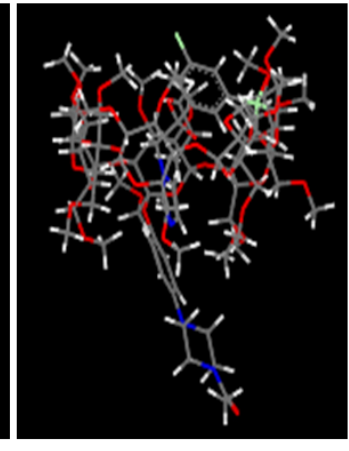

2R4S

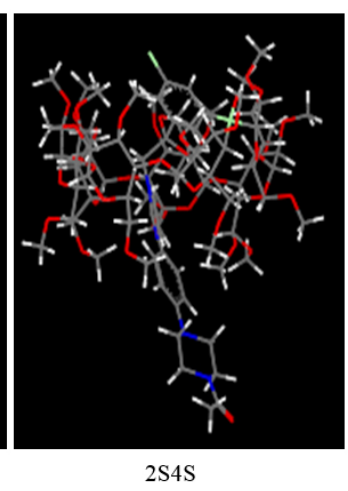

Fig. 7 Ketoconazole stereoisomers and TM $\beta C D$ complexes in 3D view with the lowest binding energy [grey: carbon; blue: nitrogen; green: chlorine; red: oxygen; white: hydrogen]

\section{CONCLUSION}

An experimental and theoretical study of chiral separation of ketoconazole and TM $\beta C D$ was explored in this current study. The enantiomers of ketoconazole were resolved within less than 7 min with $R_{s}=1.79$ using low concentration of phosphate buffer $(10 \mathrm{mM})$ in CD-EKC method. Random inclusion complexation of ketoconazole stereoisomers into the TM $\beta C D$ cavity was successfully determined for the most favourable complex for each stereoisomer with the lowest binding energy using PM3 and Gaussian 03 calculations.

\section{ACKNOWLEDGEMENT}

The authors gratefully acknowledged Universiti Teknologi Malaysia for the Tier 1 Research University Grant (vote no. 04H22) and Ministry of Higher Education Malaysia for MyPhD award to S. R. Arsad.

\section{REFERENCES}

[1] J. Heeres, L. J. J. Backx, J. H. Mostmans, and J. Van Cutsem, J. Med. Chem., 8 (1979) 1003. 
[2] D. M. Rotstein, D. J. Kertesz, K. A. M. Walker, and D. C. Swinney, J. Med. Chem., 35 (1992) 2818.

[3] E. Redenti, P. Ventura, G. Fronza, A. Selva, S. Rivara, P. V. Plazzi, and M. Mor, J. Pharm. Sci., 88 (1999) 599.

[4] A. Thienpont, J. Gal, C. Aeschlimann, and G. Félix, Analusis, 27 (1999) 713.

[5] I. Velikinac, O. Cudina, I. Janković, D. Agbaba, and S. Vladimirov, IL Farmaco, 59 (2004) 419.

[6] K. Altria, A. Marsh, and C. Sänger-van de Griend, Electrophoresis, 27 (2006) 2263.

[7] W.A. Wan Ibrahim, S.A. Warno, D. Hermawan, M.M. Sanagi, Electrophoresis, 30 (2009) 1976

[8] B. Koppenhoefer, X. Zhu, A. Jakob, S. Wuerthner, and B. Lin, J. Chromatogr. A, 875 (2000) 135.

[9] M.J. Frisch, G.W. Trucks, H. B. Schlegel, G.E. Scuseria, M.A. Robb, J. R. Cheeseman, J. A. Montgomery, Jr., T. Vreven, K. N. Kudin, J. C. Burant, J. M. Millam, S. S. Iyengar, J. Tomasi, V. Barone, B. Mennucci, M. Cossi, G. Scalmani, N. Rega, G. A Petersson, H. Nakatsuji, M. Hada, M. Ehara, K. Toyota, R. Fukuda, J. Hasegawa, M. Ishida, T. Nakajima, Y. Honda, O. Kitao, H. Nakai, M. Klene, X. Li, J. E. Knox, H. P. Hratchian, J. B. Cross, V. Bakken, C. Adamo, J. Jaramillo, R. Gomperts, R. E. Stratmann, O. Yazyev, A. J. Austin, R. Cammi, C. Pomelli, J. W. Ochterski, P. Y. Ayala, K. Morokuma, G. A. Voth, P. Salvador, J. J. Dannenberg, V. G. Zakrzewski, S. Dapprich, A. D. Daniels, M.
C. Strain, O. Farkas, D. K. Malick, A. D. Rabuck, K Raghavachari, J. B. Foresman, J. V. Ortiz, Q. Cui, A. G. Baboul, S. Clifford, J. Cioslowski, B. B. Stefanov, G. Liu, A. Liashenko, P. Piskorz, I. Komaromi, R. L. Martin, D. J. Fox, T. Keith, M. A. Al-Laham, C. Y. Peng, A. Nanayakkara, M. Challacombe, P. M. W. Gill, B. Johnson, W. Chen, M. W. Wong, C. Gonzalez, and J. A. Pople, Gaussian, Inc., Wallingford CT, 2004.

[10] M. Castro-Puyana, A.L. Crego, and M.L. Marina, Electrophoresis, 26 (2005) 3960.

[11] M. Castro-Puyana, A.L. Crego, M.L. Marina, and C. García-Ruiz, Electrophoresis, 28 (2007) 2667.

[12] D. Hermawan, W. A. Wan Ibrahim, M. M. Sanagi, and H. Y. Aboul-Enein, J. Pharm Biomed Anal, 53 (2010) 1244.

[13] M. Károly, J. Vámos, A. Nemes, A. Rácz, and B. Noszál, J. Chromatogr A, 996 (2003) 195.

[14] J.J Passos, F.B. De Souza, I. S, Lula, E.A. Barreto, J.F. Lopes, W. B. De Almeida, and R.D. Sinisterra, Int. J. Pharm., 421 (2011) 24.

[15] K.M. Al Azzam, B. Saad, R. Adnan, M. I. Saleh, Microchim. Acta 166 (2009) 311 .

[16] J.L. Bernal, L. Toribio, M.J. del Nozal, E.M. Nieto, M.I Montequi, J. Biochem. Biophys. Methods, 54 (2002) 245.

[17] X. Lin, C. Zhu, and A. Hao, Electrophoresis, 26 (2005) 3890. 